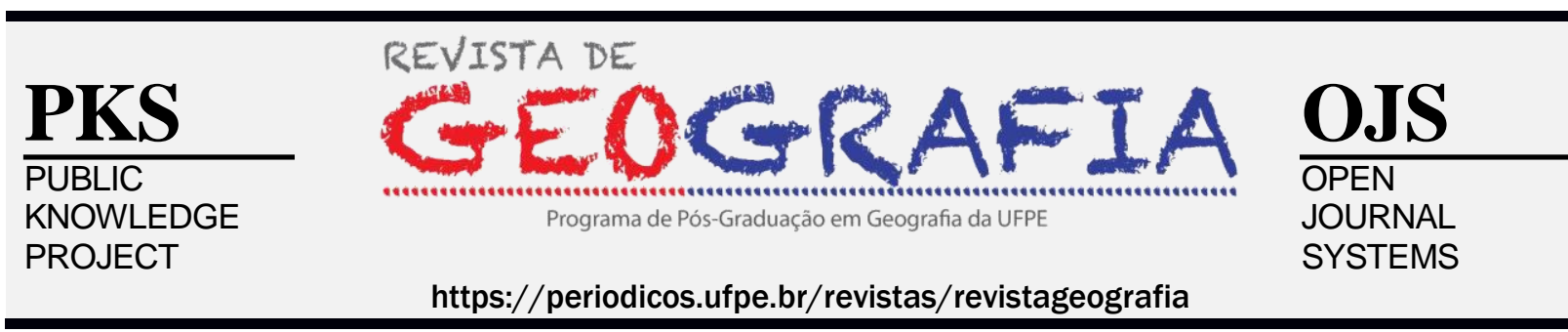

\title{
ORGANIZAÇÃO ODEBRECHT: DA CONSTRUÇÃO CIVIL MUNDIAL A EDUCAÇÃO PELO TRABALHO NO CAMPO BAIANO
}

\author{
Aline dos Santos Lima ${ }^{1}$ \\ ${ }^{1}$ Professora de Geografia do IF Baiano Campus Santa Inês.Coordenadora do Núcleo de Estudos em Questões \\ Agrárias/IF Baiano/CNPq. Pesquisadora do Geografar/POSGEO/UFBA/CNPq. E-mail: \\ aline.lima@ifbaiano.edu.br
}

Artigo recebido em 23/12/2018 e aceito em 09/03/2019

\begin{abstract}
RESUMO
O processo histórico de formação do território brasileiro ensejou a coexistência de grupos sociais que se reproduzem numa relação desigual na qual a riqueza é concentrada entre poucos e a pobreza compartilhada por muitos, especialmente no campo. Essa relação desigual tem promovido disputas por modelos distintos de sociedade, além do uso da violência que se manifesta na exclusão e expropriação, não somente do acesso à terra, mas também do acesso ao conhecimento e a possibilidade de desenvolvimento pleno do modo de vida. Esse histórico de violência tem adquirido um tom diferente, especialmente quando frações do capital vem assumindo formas cada vez mais elaboradas para subordinar o trabalhador do campo ao dificultar a luta pela/na terra. Desse modo, o objetivo desse trabalho é analisar como a Organização Odebrecht vem recriando os mecanismos de subordinação no campo a partir da junção entre as dimensões do educar e do trabalhar. Para tanto, a holding Odebrecht S.A. difundiu um modelo de educação pelo trabalho a partir da criação de cinco projetos educacionais e de geração de trabalho e renda que agregam a escolarização e o trabalho como pilares.
\end{abstract}

Palavras-chave: Organização Odebrecht; questão agrária; educação corporativa.

\section{ODEBRECHT ORGANIZATION: FROM GLOBAL CIVIL CONSTRUCTION TO EDUCATION FOR WORK IN THE BAHIA COUNTRYSIDE}

\begin{abstract}
The historical process of formation in Brazilian territory has brought coexistence of social groups that reproduce in an unequal relationship in which wealth has been concentrated with few and the poverty has been shared by many, especially in the countryside. This unequal relationship has been promoted disputes for different models of society, as well as the use of violence that has manifested in the exclusion and expropriation, not only of access to land, but also of access to knowledge and the possibility of full development of the way of life. This violence historical has acquired a different tone, especially when fractions of capital have been taking on increasingly elaborate ways to subordinate the farm worker making it difficult to fight for/on the land. In this way, this objective work is analyzing how the Odebrecht Organization has been recreating the subordination mechanisms in the field from the junction between the dimensions of educating and working. To that end, Odebrecht S.A company has disseminated a model of work education through the creation of five educational projects and work generation and income that combine schooling and work as pillars.
\end{abstract}

Keywords: Odebrecht Organization; agrarian issue; corporative education. 


\section{INTRODUÇÃO}

A concentração da propriedade da terra no Brasil tem origens históricas que se reproduzem com a expansão do modo de produção capitalista no campo. Tal processo, permite afirmar que a questão agrária é uma problemática que acompanha o momento presente. Por questão agrária se entende as questões relativas às relações sociais de produção, ou seja, envolve, dentre outros, como e de que forma se produz no campo. Aspectos que remetem à estrutura de propriedade da terra e às relações sociais de produção que são estabelecidas entre os distintos e antagônicos grupos sociais que coexistem no tempo-espaço (GERMANI, 2009, 2010).

É possível afirmar que os grupos sociais que coexistem no tempo-espaço do campo brasileiro se reproduzem numa relação desigual que, ao mesmo tempo, promove a concentração da riqueza e o aumento da pobreza e da miséria. Portanto, estes distintos sujeitos estão em disputa por modelos de sociedade. Como tão bem afirmou Camacho (2013, p. 750), "todas as dimensões da realidade estão sendo disputadas: a educação, a cultura, a política, o controle sobre a produção, distribuição, circulação e consumo etc. São disputas por modelos distintos de sociedade e pela construção de territórios antagônicos".

Em determinados contextos espaço-temporais, essas disputas foram caracterizadas pela violência, pela exclusão e pela expropriação, não somente do acesso à terra, mas também do acesso ao conhecimento e da possibilidade de desenvolvimento pleno do modo de vida, em especial daqueles que tem no espaço rural as bases de sua existência material e simbólica. Portanto, é válido considerar que a questão agrária brasileira é o principal processo que serve de base para a construção de uma educação transformadora e revolucionária (KUHN, 2015).

Contudo, essas disputas têm adquirido um tom diferente. A escravidão, a monocultura e o latifúndio, que por muito tempo expropriou e tratou o campesinato com violência, deu lugar a processos mais complexos de obtenção da renda da terra e da sujeição do trabalho ao capital com inovações tecnológicas e maior produtividade. As últimas décadas do século XX marcaram esse momento histórico do capitalismo em sua fase monopolista (OLIVEIRA 1986, 2007; KUHN, 2015) através de contratos de integração entre o campesinato e grandes corporações (SANTOS, 1978; SANDRONI, 1980; SORJ et al., 1982; WANDERLEY, 1985; ETGES, 1991; PAULINO, 2003; CONCEIÇÃO, 2007; PERTILE, 2008; BELUSSO, 2011).

No bojo desse movimento, se conforma um processo ainda mais complexo. O capital vem assumindo formas cada vez mais elaboradas para subordinar o trabalhador do campo ao dificultar a luta pela/na terra. Assim, frações do capital, com a anuência do Estado, ao invés 
de excluir e expropriar o campesinato através da produção de commodities, passou a adotar outras estratégias, em especial ao recriar os mecanismos de subordinação (LIMA, 2017).

Nesse sentido, a violência como "prática de classe" deixa de ser apenas física e passa a ser, também, simbólica. Ou seja, é "uma violência estruturante" que expõe "velhos e novos padrões de conduta e de pensamento, e impede o reconhecimento do outro mediante o uso da força ou da coerção" (BRUNO et al., 2010, p. 523). A pauta não é expulsar do campo, mas recriar o camponês dentro de um modelo de desenvolvimento no qual ele se qualificará (educação), incorporará tecnologia e se integrará ao mercado (trabalho) em consonância com as expectativas do capital, mas permanecerá sem a posse da terra e terá seus saberes desqualificados (LIMA, 2017).

Desse modo, o objetivo desse artigo é analisar como a Organização Odebrecht vem recriando os mecanismos de subordinação no campo a partir da junção entre as dimensões do educar e do trabalhar. Para descortinar essa problemática, o procedimento adotado foi a "metodologia pés no chão". Esta metodologia consiste na forma de fazer pesquisa e de fazer extensão no âmbito do Projeto Geograf $\mathrm{AR}^{1}$, ou seja, uma junção entre observações, oficinas, entrevistas e representações cartográficas. Acrescenta-se, ainda, a leitura e a discussão de textos sobre educação na perspectiva do capital, bem como dissertações e teses cuja centralidade analítica é a Organização Odebrecht. Além disso, foram valiosíssimas as publicações editadas pela própria Odebrecht, assim como outras produções de autoria de Norberto Odebrecht, considerado nesses documentos como “o fundador” da empresa.

A partir desse processo, identificou-se que a Organização Odebrecht difundiu um modelo de educação pelo trabalho a partir da criação de cinco projetos educacionais e de geração de trabalho e renda como pilares de sua territorialização no campo baiano. Para compreender as intencionalidades dessa intervenção, capitaneada por uma holding que tem como "carro-chefe" a engenharia/construção civil e, em segundo lugar, a química/petroquímica, é preciso entender o significado político das múltiplas expressões da educação na perspectiva do capital.

\footnotetext{
${ }^{1}$ O Projeto Integrado de Pesquisa "A Geografia dos Assentamentos na Área Rural" - Projeto GeografAR - vem, desde 1996, desenvolvendo pesquisas com o propósito de analisar o processo de (re) produção do espaço geográfico no campo baiano em suas distintas temporalidades, espacialidades e territorialidades tendo como pressuposto a permanência da questão agrária. 


\section{ORGANIZAÇÃO ODEBRECHT E A EDUCAÇÃO PELO TRABALHO}

Ao longo de sua vida como engenheiro-empresário, Norberto Odebrecht (1920-2014) construiu uma "filosofia empresarial" com o propósito de formar todos aqueles que mantinham relação com os negócios da Organização Odebrecht. Assim, foram construídas as bases práticas e teóricas da chamada Tecnologia Empresarial Odebrecht (TEO). A TEO tem como propósito difundir para todos os integrantes da corporação um "conjunto de princípios, conceitos e critérios", bem como os "fundamentos éticos, morais e conceituais" que regem a empresa (ODEBRECHT, 1991; ORGANIZAÇÃO ODEBRECHT, 2015).

Os princípios de gestão da Organização Odebrecht se caracterizam pela “descentralização", “delegação planejada” e a "parceria”. Esse tripé já existia desde os anos 1940, quando o jovem Norberto assume os negócios da família². Mas, é a partir dos anos 1980, com a criação da holding Odebrecht S.A. ${ }^{3}$ que passam a vigorar com mais ênfase.

O resultado de todo esse processo é que, entre 1944 e 2016, a Organização Odebrecht expandiu geograficamente e diversificou sua carteira de investimentos. Além disso, a corporação se territorializou no Brasil e em outros 35 países com investimentos em diversos ramos setorizados em negócios liderados por 14 grandes empresas, 4 empresas qualificadas como auxiliares e 3 fundos de investimentos, sem contar a Fundação Odebrecht, o "braço" social da Organização (ORGANIZAÇÃO ODEBRECHT, 2016).

Assim, da mesma forma que Norberto Odebrecht construiu uma "filosofia empresarial" para o mundo dos negócios, ele construiu uma filosofia educacional para as ações sociais levadas a cabo pela Fundação. Tanto a "filosofia empresarial" quanto a educacional são pautadas no princípio da educação pelo trabalho, o que, por sua vez, tem

\footnotetext{
${ }^{2}$ Norberto é o principal representante da quarta geração da família Odebrecht. Esta chegou ao Brasil, vindo da Pomerânia, atual estado de Mecklemburgo-Pomerânia Ocidental, em 1856. Norberto Odebrecht ingressa no curso de engenharia na então Escola Politécnica de Salvador (1938-1943), mas, antes de concluir os estudos, assume os negócios da família (1941), pois, em decorrência da Segunda Guerra Mundial (1939-1945), os materiais de construção vindos da Europa tornaram-se caros e escassos, deflagrando uma crise no setor. Com a falência da empresa do pai, o jovem assume os negócios e, quando tinha 24 anos, cria a firma Norberto Odebrecht Construtora Ltda. (1944), que, depois passa a se chamar Construtora Norberto Odebrecht S.A (1954) (ODEBRECHT, 1991, 2004; REVISTA ODEBRECHT INFORMA, 2004; ORGANIZAÇÃO ODEBRECHT, 2015).

${ }^{3}$ A holding Odebrecht S.A. é uma agregação de pequenas empresas ligadas entre si "por laços confederativos". Cada pequena empresa que compõe a Organização se constitui como um "espaço de formação" para os colaboradores (ODEBRECHT S.A., 2013), o que sustenta a existência de um "Sistema Educacional Odebrecht". Este sistema é baseado na conexão de saberes entre pessoas de diferentes gerações ou idades, quais sejam: a) "jovens de talento" (primeira idade), recém-saídos da educação familiar e que assumem a função "empresarialoperacional"; b) "pessoas amadurecidas" (segunda idade), que ocupam posição de liderança e são responsáveis pelo segmento "estratégico-empresarial"; c) "seres humanos experimentados pela vida" (terceira idade), que detém "sabedoria prática" para transmitir aos demais e assume o papel "político-estratégico" (ODEBRECHT, 1991; REVISTA ODEBRECHT INFORMA, 2004).
} 
relação com a formação familiar e religiosa do seu idealizador ${ }^{4}$ (ODEBRECHT, 1991; GONÇALVES, 2003; JACOBINA, 2008; LIMA, 2017).

Para além disso, a educação pelo trabalho proposta por Norberto Odebrecht tem uma relação estreita com a questão agrária. Na Geografia, “é comum a expressão 'questão agrária' para explicar a forma como as sociedades e as pessoas vão se apropriando da utilização do principal bem da natureza, que é a terra, e como vai ocorrendo a ocupação humana no território" (STEDILE, 2011, p. 15). Para entender como a Organização Odebrecht vem recriando os mecanismos de subordinação em defesa de um projeto de sociedade favorável ao capital, é preciso discutir as múltiplas expressões da educação na perspectiva das frações do capital.

\section{BREVE DIGRESSÃO SOBRE A EDUCAÇÃO NA PERSPECTIVA DO CAPITAL}

Para se compreender as investidas da Organização Odebrecht em projetos educacionais e de geração de trabalho e renda no estado da Bahia, é preciso discutir um pouco os significados da educação na perspectiva do capital. Somente assim, é possível descortinar as intencionalidades que estão por trás da oferta de escolarização no campo como mecanismo para subordinar, ainda mais, o trabalhador a lógica do capital.

A reflexão sobre a oferta de educação no campo pela Organização Odebrecht exige algumas considerações sobre o que se convencionou chamar de educação corporativa. De acordo com Tiradentes (2012, p. 247; 249), a educação corporativa corresponde a um modelo de formação que surgiu nos Estados Unidos, na década de 1950. Neste modelo, a empresa ocupa o lugar da escola, desenvolvendo programas de "educação formal, informal e não formal de trabalhadores, de fornecedores e da comunidade, para aumento de produtividade, valorização do capital de marca e como estratégia hegemônica de difusão da concepção de mundo da classe dominante". O objetivo inicial da educação corporativa era "treinar os trabalhadores de algumas indústrias". Sua origem tem relação direta com a estratégia de negócios e com o sistema de formação de pessoas com base em competências vinculadas aos propósitos, valores, objetivos e metas empresariais.

\footnotetext{
${ }^{4}$ É importante acrescentar que desde a infância, Norberto Odebrecht aprendeu a conciliar educação e trabalho. Segundo o próprio engenheiro-empresário, sua infância foi marcada por uma rígida educação luterana e uma formação que mesclava conhecimentos teóricos (educação) e práticos (trabalho) (ODEBRECHT, 1991; JACOBINA, 2008). Ainda criança, tinha aulas particulares com um preceptor luterano (pastor Arnold), no bairro de Nazaré - na época o "mais rico da Bahia" (JACOBINA, 2008). Concomitantemente, frequentava os canteiros de obras na região da Pituba, então periferia da cidade de Salvador formando-se como um "aprendiz de empresário" (ODEBRECHT, 1991, p. 116). 
A noção das competências se fundamenta em teorias educacionais que visam atender ao sistema capitalista. Para isso, é necessário a construção de um modelo educativo que valorize a produtividade e a competitividade, valores a serem alcançados numa educação cuja ideologia atenda às classes dominantes. Como disse Camacho (2013, p. 661), o objetivo é ir moldando o "comportamento das classes subalternas de acordo com as necessidades do capital em sua fase da acumulação flexível", basta que essas competências sejam difundidas por meio "de técnicas a serem apreendidas por uma metodologia de ensino-aprendizagem que garanta o seu desenvolvimento, o adapte as transformações atuais e o inclua de maneira subalterna no modo de produção capitalista".

Esse formato de educação, baseado na pedagogia das competências, visa manter a exclusão social das camadas populares. Sendo assim, o que se apresenta como concessão de um direito social é, na verdade, a difusão da ideologia neoliberal que, ao invés de engendrar um projeto de emancipação humana

(...) pode levar a reprodução de uma ideologia que faz com que as classes subalternas pensem que estão livres emancipados por estarem se apropriando do direito a educação, que foi historicamente negado, quando na verdade é mais uma forma de garantir a manutenção da lógica desigual do capital (CAMACHO, 2013, p. 744).

No contexto neoliberal, a educação corporativa adquiriu maior expressão atrelada a duas questões inter-relacionadas. De um lado, a ideologia de desqualificação do Estado social, abrindo espaço para que outros sujeitos assumissem funções que até então eram suas. Do outro, as mudanças nas bases técnicas e de gestão que exigem do trabalhador a incorporação dos valores das empresas. A junção desses dois aspectos fez com que um número cada vez maior de corporações passasse a promover programas de formação intelectual e técnica dos seus funcionários sempre em aderência a lógica do capital (TIRADENTES, 2012).

Vale lembrar que, no Brasil, o início dos anos 1990, foi marcado pela junção de vários processos que culminaram no comportamento social do setor privado, dentre os quais: abertura da economia; privatização das empresas estatais; crise política e econômica; fortalecimento da sociedade civil; maior envolvimento das organizações não-governamentais; busca de melhoria na qualidade dos processos de gestão das empresas nacionais, acompanhado de mudanças no mercado de trabalho, redução na capacidade de atuação do 
Estado e no crescente envolvimento das empresas privadas em ações sociais ${ }^{5}$ (PELIANO, 2011).

Dentre os aspectos elencados, atribui-se relevância as mudanças no mercado de trabalho e a abertura da economia. O primeiro, teve importante relação com a introdução de novas tecnologias. Em meio a esse processo, houve um aumento do desemprego, o crescimento da informalidade e a terceirização das atividades de produção. Por outro lado, o Estado já não conseguia responder as crescentes demandas da sociedade (PELIANO, 2011). Nesse bojo, ganharam força as teses que sustentam a formação de novos agentes sociais, como as empresas privadas (PELIANO, 2001) e as organizações não-governamentais (SILVA, 2002).

Foi justamente esse contexto que permitiu a difusão da educação pelo trabalho da Organização Odebrecht para além dos muros das empresas que integram a holding. Esse processo se deu de duas formas. Uma delas foi a implementação de projetos educacionais e de geração de trabalho e renda pela Fundação Odebrecht (ODEBRECHT S.A., 2013, p. 7). A outra, a título de informação, se refere ao processo de formação de mão de obra para ser ligada a um dos vários negócios da Organização ${ }^{6}$.

A educação pelo trabalho promovida pela Fundação Odebrecht através dos projetos educacionais e de geração de trabalho e renda, no interior da Bahia, também pode ser pensada como uma concepção de educação neoliberal no campo ou educação do capital. A educação do capital propõe "formar sujeitos que sejam funcionais à reprodução do capital, buscando inculcar ideologias dominantes, contribuindo para a perpetuação das desigualdades sociais e manutenção da sociedade de classes", ou seja, está voltada para a formação de jovens rurais com o propósito de construir um "agronegócio inclusivo" ou uma "agricultura familiar empreendedora" (CAMACHO, 2013, p. 348; 702).

\footnotetext{
${ }^{5}$ É importante registrar, que o comportamento social ou a responsabilidade social do setor privado se refere à maneira pela qual o empresariado "participa de ações sociais de caráter público" como, por exemplo, através de "atividades ou doações não obrigatórias realizadas pelas empresas para atender ou ajudar a comunidade com serviços de assistência, alimentação, saúde e educação, entre outros" (PELIANO, 2001, p. 13; 26). Por muito tempo, essas práticas não eram de conhecimento público devido ao baixo interesse das empresas e da mídia na sua divulgação, bem como pela escassez de trabalhos acadêmicos sobre o assunto, o que passa a mudar justamente a partir dos anos 1990, o que desembocou no crescimento do número de empresas que adquiriram o comportamento dito social.

${ }^{6}$ A Organização Odebrecht possui um programa institucional voltado para o desenvolvimento de pessoas em parceria com universidades e centros de formação como, por exemplo, o Programa Acreditar e o Programa Acreditar Júnior. Esses programas visam qualificar e contratar a população local em cada região onde a empresa se instala, seja no Brasil ou no exterior, envolvendo adultos (Programa Acreditar) e jovens (Programa Acreditar Júnior). No Brasil, em parceria com o antigo Ministério do Desenvolvimento Social e Combate à Fome, os Programas priorizaram os beneficiários do Programa Bolsa Família do governo federal (ODEBRECHT S.A., 2015, 2014, 2013, 2012, 2011, 2010). Entre 2008-2014, o Programa Acreditar possibilitou a contratação, pela Odebrecht, de 3.034 pessoas que participaram das ações de qualificação (ODEBRECHT S.A., 2015, p. 33). 
Com base em Kuhn (2015), é possível observar que o modelo de educação pelo trabalho se aproxima da chamada educação rural. Não que a filosofia educacional do Organização Odebrecht esteja associada à precariedade e a má qualidade típica desse modelo histórico. O ponto em comum é fruto do ciclo de retorno da educação rural que avançou nos aspectos práticos, mas reproduz o modelo produtivista do campo, pois permanece com pouca crítica da realidade, prossegue com a escolarização descontextualizada e, principalmente, mantem a ausência de preocupação com a transformação das relações sociais e econômicas.

Seja com o nome educação corporativa, educação neoliberal, educação do capital ou educação rural, o que importa é que esses modelos têm algo em comum: os camponeses não são protagonistas do processo, porque continuam sendo subalternos aos interesses do capital. Significa, também, que quando o capital passa a propor o ensino para o campesinato existe uma disputa teórica-política-ideológica pela educação.

Essas disputas perpassam também no âmbito das políticas públicas, especialmente com a criação do Programa Nacional de Educação do Campo (PRONACAMPO), em 2012. Esse Programa expressa uma contradição por destoar da "radicalidade pedagógica" pleiteada pelo campesinato organizado (CALDART, 2010) e agregar tanto o Programa de Apoio à Formação Superior em Licenciatura em Educação do Campo (PROCAMPO) quanto o Programa Nacional de Acesso ao Ensino Técnico e Emprego (PRONATEC). Este último, indica a hegemonia do capital, pois tem o Serviço Nacional de Aprendizagem Rural (SENAR) e a Confederação da Agricultura e Pecuária do Brasil (CNA) como seu principal formulador e, além disso, atende a lógica da formação técnico-profissional com o objetivo de garantir a preparação da mão de obra para o agronegócio e/ou diminuir os focos de conflito com os camponeses. Ou seja, é uma política de educação profissional que serve ao mercado (FONEC, 2012; KUHN, 2015).

A disputa pelo território da educação no campo pode ser explicitada, também, a partir dos princípios que lhe sustenta. No caso da educação na perspectiva do capital, os princípios demarcam a "perspectiva ideológica da classe dominante" e são "convenientes ao capital e à reprodução de seu modo de produção da existência" (TIRADENTES, 2012, p. 248). Nesse caso, prevalecem a competitividade, a conectividade, a parceria, a perpetuidade, a cidadania, a sustentabilidade e a disponibilidade (ÉBOLI apud TIRADENTES, 2012).

Para Caldart (2010, p. 115-116), existem três razões principais para explicar a entrada do capital na disputa pela educação do campo. A primeira razão seria a chamada reestruturação produtiva que exige uma mão de obra cada vez mais qualificada. Essa demanda 
faz com que o empresariado rural passe a discutir a formação e a educação profissional. $O$ segundo motivo está relacionado a chamada modernização da agricultura. Esse contexto, faz com que a escolarização básica para o chamado agricultor familiar passe a ser aceita, pois significa a formação de "exército de reserva" para as empresas que comandam os negócios agrícolas. Além disso, possibilita que o Estado, ao invés de construir um sistema público de educação no próprio campo, possa atender às demandas específicas do capital. O terceiro motivo apresentado pela autora, está relacionado ao fato de que o empresariado rural passou a entender que as escolas são um excelente veículo de difusão da ideologia do agronegócio.

Na opinião de Tiradentes (2012, p. 250), há muitos conglomerados vinculados à produção agropecuária, executando a chamada educação corporativa no Brasil. A difusão desse modelo no "território da formação humana" tem provocado a "descaracterização dos movimentos sociais" e a incorporação de uma "ideologia pactualista que desqualifica a ação das lutas no campo e na cidade".

Para Camacho (2013, p. 743), o ingresso de frações do capital na seara da educação tem relação com a "ideologia da responsabilidade social". Com esse discurso, importantes corporações favorecem suas "cadeias produtivas" ao criar institutos que conseguem "realizar uma tripla intencionalidade: formar seus fornecedores (...) difundir a sua visão de mundo para o restante da sociedade e fazer um marketing da empresa valorizando seu status diante do mercado".

É possível identificar distintos grupos econômicos enveredando pela lógica utilitarista da educação. A Bayer tem realizado experimentos de transgenia ao mesmo tempo em que apoia práticas agroecológicos dos pequenos produtores. A Basf, uma das maiores fabricantes de agrotóxicos do mundo e representante dos interesses do agronegócio, apoiam iniciativas que legitimam a importância da população do campo $^{7}$. A Monsanto, por sua vez, tem produzido materiais didáticos, sobre agricultura e meio ambiente, que são difundidos em cursos de formação para professores ofertados em parceria com universidades e secretarias de educação. Já a Souza Cruz, possui um Instituto responsável pela oferta de cursos voltados para o empreendedorismo do jovem rural. Por sua vez, a Vale tem promovido a capacitação e a formação através da Valer, uma universidade corporativa da empresa (TIRADENTES, 2012; CAMACHO, 2013).

\footnotetext{
${ }^{7}$ Em 2013, por exemplo, a Basf patrocinou a escola de samba "Unidos de Vila Isabel", associando sua imagem com a biodiversidade já que o tema do samba-enredo cantou "Brasil celeiro do mundo, água no feijão que chegou mais um..." (GRÊMIO RECREATIVO ESCOLA DE SAMBA UNIDOS DE VILA ISABEL, 2013). 
De modo semelhante a Organização Odebrecht, outras empresas globais de "capital nacional", que igualmente exploram a construção civil, o mercado imobiliário, as concessões de serviços públicos, o petróleo e gás e as finanças, investem, também, no campo brasileiro. Porém, essas empresas intervêm no campo, exclusiva e diretamente, em busca de lucro, ou seja, não têm o propósito de criar e implementar projetos que atendam as populações pobres do campo. Esse é o caso da Queiroz Galvão e da Votorantim que atuam em frações do capital como a silvicultura e a produção de alimentos (frutas, pescados e gado) integrando agricultura e pecuária à indústria.

Contudo, a proposição da educação pelo trabalho da Organização Odebrecht antecede, e muito, essa cronologia. O diferencial é que a Organização Odebrecht vem realizando suas estratégias de responsabilidade social e marketing há bastante tempo, antes dessas ações se tornarem "moda", o que estaria relacionado com as características de personalidade de Norberto Odebrecht. Portanto, cabe atentar que a inculcação da ideologia dominante não está dada, ela é construída.

\section{A TERRITORIALIZAÇÃO DOS PROJETOS EDUCACIONAIS E DE GERAÇÃO DE TRABALHO E RENDA DA FUNDAÇÃO ODEBRECHT NO CAMPO BAIANO: SERRA DA PIPOCA, BAIXO SUL E VALE DO JIQUIRIÇÁ}

Os projetos educacionais e de geração de trabalho e renda criados pela Fundação Odebrecht são voltados para comunidades rurais. Esta modalidade, que só existe na Bahia, foi materializada em contextos espaço-temporais distintos.

A primeira experiência ocorreu entre as décadas de 1980-1990, através da aquisição de terras para a criação e o funcionamento de um complexo agroindustrial nos municípios de Iramaia (Fazenda Serra da Pipoca) e de Manuel Vitorino (Indústria Kieps), sob o comando da então Fundação Emílio Odebrecht (PRATA, 1994).

O complexo agroindustrial da família Odebrecht fazia a integração entre agropecuária e indústria através do plantio e do processamento de vários produtos cultivados na região, como aspargo, beterraba, cenoura, maxixe, milho verde, pepino, dentre outros. Os lavradores, como eram chamados os camponeses, trabalhavam em suas próprias terras. Contudo, o processo produtivo, até então realizado com técnicas "primitivas" e temporalidade sazonal, precisou ser modificado para um ritmo de trabalho intensivo, o que ficou a cargo da Fundação. Toda produção dos lavradores era entregue a Indústria Kieps com o intermédio da Associação Pró-Lago, criada para esse fim (PRATA, 1994). 
A experiência inicial na Fazenda Serra da Pipoca e na Indústria Kieps, traça as normas que caracterizariam as futuras intervenções da Fundação Odebrecht no campo baiano. Ainda na década de 1990, os lavradores foram convidados a participar de um processo de qualificação (educação) com vistas a se integrar ao sistema de parceria agrícola articulado por uma associação (trabalho). Esse processo vigorou até 1997, quando o complexo agroindustrial foi transformado em Fazendas Reunidas Rio de Contas Ltda. Com essa mudança, a TEO é incorporada na gestão e no funcionamento das novas atividades produtivas (RIOCON, 2014).

Essa primeira experiência foi "rascunho" das relações que seriam aperfeiçoadas pela Fundação Odebrecht, na década de 2000, em municípios do Baixo Sul da Bahia ${ }^{8}$. É importante registrar que a Fundação Emílio Odebrecht foi criada em dezembro de 1965. Em seus primeiros 23 anos, suas ações eram restritas aos integrantes da Construtora Norberto Odebrecht (FUNDAÇÃO ODEBRECHT, 2013; ORGANIZAÇÃO ODEBRECHT, 2015).

Em 1988, a Fundação muda de nome e de foco. Passa a se chamar Fundação Odebrecht e "redireciona o foco de sua atuação para a educação de jovens" (ODEBRECHT S.A., 2014, p. 14). Uma década depois, a Fundação construiu uma parceria, com o Instituto Ayrton Senna, a Fundação Kellogg e a Área Social do Banco Nacional de Desenvolvimento Econômico e Social, dando origem ao Instituto Aliança, cujo objetivo era promover ações em prol de jovens que vivessem em condições de vulnerabilidade nas regiões da Bacia do Goitá (Pernambuco), Baixo Sul (Bahia) e Médio Jaguaribe (Ceará) (FUNDAÇÃO ODEBRECHT, 2011, p. 8).

Entre 1999-2004, sob a coordenação do Instituto Aliança, a população daqueles municípios foram alvo das ações do "Projeto Aliança com o Adolescente pelo Desenvolvimento Sustentável do Nordeste" (SILVA, 2002; FISCHER, 2007; CNPMF, 2010). Após a conclusão do Projeto, o Conselho de Curadores da Fundação Odebrecht decidiu pela permanência na Bahia e delimitou o Baixo Sul como área de atuação para os projetos educacionais e de geração de trabalho e renda. Contudo, o público-alvo deixa de ser apenas o indivíduo (jovem ou adolescente) e passa a englobar todo o núcleo familiar, ou melhor, a "unidade-família".

É esse o contexto no qual Norberto Odebrecht passa a teorizar sobre sua filosofia educacional. Desse modo, é criada a expressão Aliança Estratégica. Uma Aliança Estratégica

\footnotetext{
8 O Território Baixo Sul é formado por 15 municípios: Aratuípe, Cairu, Camamu, Gandu, Ibirapitanga, Igrapiúna, Ituberá, Jaguaripe, Nilo Peçanha, Piraí do Norte, Presidente Tancredo Neves, Taperoá, Teolândia, Valença e Wenceslau Guimarães (SEPLAN, 2015). 
é uma abstração, um conceito criado e difundido pelo seu idealizador para territorializar sua concepção filosófica de educação pelo trabalho no campo.

Essa territorialização ocorre em propriedades rurais que abrigam um conjunto de fixos, chamados de módulo ou complexo agroindustrial, e que tem como função implementar os projetos educacionais e de geração de trabalho e renda. Cada projeto se conforma filosófica, popular e juridicamente do seguinte modo:

a) na perspectiva filosófica, tem um nome conceitual (Aliança Estratégica do/da...);

b) popularmente tem, ou pode ter, um nome fantasia que é o nome como a projeto é conhecido na sociedade;

c) e, no aspecto jurídico, possui uma, duas ou até três pessoas jurídicas, como, por exemplo, uma cooperativa, uma indústria e uma instituição de ensino.

Os entes jurídicos agregam as instituições que materializam os projetos educacionais e de geração de trabalho e renda. Desse modo, a dimensão do trabalho se conforma a partir da criação de cooperativas formadas por camponeses que compõem aquilo que seus idealizadores entendem como setor primário. Este setor é responsável organização produtiva em segmentos agrícola/aquícola/extrativista, sempre utilizando um pacote de alta tecnologia (insumos químicos, sementes modificadas em laboratório, rações e mecanização).

Toda produção do setor primário é adquirida pela cooperativa que, por sua vez, comercializa a produção com o chamado setor secundário. Para tanto, são criadas unidades de beneficiamento/indústrias que se encarregam de fazer o processamento dos subprodutos, além de assumir a condição de setor terciário ao fazer a comercialização dos mesmos com valor agregado. Por fim, existem as instituições de ensino encarregadas de ofertar a educação formal (regular) e informal para os membros das "unidades-família". Todo esse processo pode ser esquematizado do seguinte modo:

a) ingresso de "unidades-famílias" pobres e excluídas no processo formativo (educação) e produtivo (trabalho). Os adultos, normalmente os chefes da "unidade-família", se qulificam em programas complementares de formação (educação informal) e jovens/adolescentes são convidados a fazer o curso técnico integrado ao ensino médio em escolas regulares (educação formal);

b) o/a chefe da "unidade-família" ingressa numa cooperativa. Com a ajuda de todos os membros, o/a cooperado/a produz determinada lavoura/criatório. Toda produção é repassada para a cooperativa que, por sua vez, encaminha a produção para 
beneficiamento na unidade industrial e posterior comercialização. O fluxo desse sistema tem o objetivo de qualificar as "unidades-família" através da educação pelo trabalho e retroalimentar o "círculo virtuoso": filhos de agricultores pobres emergem para a classe média rural (FUNDAÇÃO ODEBRECHT, 2011, p.23).

Em 2009, a Fundação ampliou o projeto para outros municípios baianos que estavam "fora do eixo" já consolidado no Baixo Sul. Nesse sentido, o Baixo Sul continua relevante, mas há um avanço para os Territórios de Identidade Vale do Jiquiriçá e Recôncavo a partir da implementação de um projeto no município de Laje (Vale do Jiquiriçá), cujas ações avançaram até Castro Alves, Conceição do Almeida, Santo Antônio de Jesus e Sapeaçu (Recôncavo), Jaguaripe e Valença (Baixo Sul) e São Miguel das Matas (Vale do Jiquiriçá).

Nesse processo, foram criados cinco projetos educacionais e de geração de trabalho e renda da Fundação Odebrecht na Bahia, conforme Quadro 1. Além desses cincos projetos, existe outro que é voltado, excluisvamente, para o setor de serviços e que tem como foco a cidade. Trata-se da Aliança Estratégica da Construção Civil que incorpora a Cooperativa dos Trabalhadores Autônomos da Construção Civil do Baixo Sul da Bahia, criada, em 2010, na cidade de Ituberá, e o Centro de Formação Profissional Construir Melhor, criado, em 2011, na cidade de Valença.

Quadro 1 - Alianças Estratégicas da Fundação Odebrecht na Bahia:

\begin{tabular}{|c|c|c|}
\hline Aliança Estratégica & Cooperativa Agroindustrial & Programa Educacional \\
\hline $\begin{array}{l}\text { Aliança Estratégica da } \\
\text { Mandioca }\end{array}$ & $\begin{array}{l}\text { Cooperativa de Produtores Rurais de } \\
\text { Presidente Tancredo Neves, em } \\
\text { Presidente Tancredo Neves (2000) }\end{array}$ & $\begin{array}{l}\text { Casa Familiar Rural } \\
\text { Presidente Tancredo, em } \\
\text { Presidente Tancredo Neves } \\
(2002)\end{array}$ \\
\hline \multirow[t]{2}{*}{$\begin{array}{l}\text { Aliança Estratégica da } \\
\text { Aquicultura }\end{array}$} & $\begin{array}{l}\text { Cooperativa Mista de Marisqueiros, } \\
\text { Pescadores e Aquicultores do Baixo Sul } \\
\text { da Bahia, em Ituberá (2003) }\end{array}$ & \multirow[t]{2}{*}{$\begin{array}{l}\text { Casa Familiar das Águas do } \\
\text { Baixo Sul da Bahia, em } \\
\text { Ituberá (2004) }\end{array}$} \\
\hline & $\begin{array}{l}\text { Cooperativa dos Aquicultores de Águas } \\
\text { Continentais, em Ituberá (2010) }\end{array}$ & \\
\hline $\begin{array}{l}\text { Aliança Estratégica } \\
\text { do Palmito }\end{array}$ & $\begin{array}{l}\text { Cooperativa dos Produtores de Palmito do } \\
\text { Baixo Sul, em Ituberá (2004) }\end{array}$ & 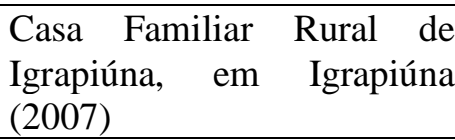 \\
\hline $\begin{array}{l}\text { Aliança Estratégica da } \\
\text { Piaçava }\end{array}$ & $\begin{array}{l}\text { Cooperativa das Produtoras e Produtores } \\
\text { Rurais da Área de Proteção Ambiental do } \\
\text { Pratigi, em Nilo Peçanha (2005) }\end{array}$ & $\begin{array}{l}\text { Casa Familiar Agroflorestal } \\
\text { do Baixo Sul da Bahia, em } \\
\text { Nilo Peçanha (2005) }\end{array}$ \\
\hline $\begin{array}{l}\text { Aliança Estratégica } \\
\text { do Amido }\end{array}$ & $\begin{array}{l}\text { Cooperativa de Produtores de Amido de } \\
\text { Mandioca do Estado da Bahia (2009) }\end{array}$ & $\begin{array}{l}\text { Instituto de Promoção } \\
\text { Humana do Amido (2013) }\end{array}$ \\
\hline
\end{tabular}

FONTE: Trabalho de campo (2014).

ELABORAÇÃO: Aline dos Santos Lima. 
Essas cinco Alianças Estratégicas, criadas entre 2000 e 2009, têm relação direta com o campo baiano, pois sua criação e funcionamento significam mudanças que afetam as comunidades rurais. Cada Aliança foi criada para atender determinada potencialidade, ou seja, corresponde a uma cooperativa e uma instituição de ensino (casa familiar e instituto) voltada para determinada "cadeia produtiva". Desse modo, as "unidades-família" são capacitadas para o desenvolvimento das competências e, com isso, aprendem a lidar com um pacote de alta tecnologia em produções agropecuárias/extrativistas até então executadas de forma convencional. Por fim, permanecem sem acesso à terra e sofrem ameaça de privatização das águas, pois o capital tem se apropriado desses bens da natureza.

Nesse plano, o modelo educativo forjado pelo capital "prepara, separa, direciona e instrumentaliza os indivíduos para funções correspondentes da divisão social do trabalho" ao passo que a família é a "unidade primordial para a sustentação das mínimas condições existenciais do trabalhador e, ainda, a reprodução geracional da própria força de trabalho" (MASCARO, 2013, p. 69).

Entretanto, a continuidade desses projetos está ameaçada. A crise política e econômica que acometeu o Estado brasileiro repercutiu enormemente na Organização Odebrecht, já que essa corporação protagoniza escândalos de corrupção e pagamento de propinas. Consequentemente, todo o aparato que sustentava os projetos educacionais e de geração de trabalho e renda enfraqueceram. Contribuiu para essa ruptura a morte do idealizador das Alianças Estratégicas, em julho de 2014. Sem a presença de Norberto Odebrecht, seus sucessores já não desprendem tanto esforço para o funcionamento dos projetos.

\section{CONSIDERAÇÕES FINAIS}

Os projetos educacionais e de geração de trabalho e renda se caracterizam pela oferta de escolarização e organização produtiva com foco na produção industrial de subprodutos com valor agregado e na qualificação dos camponeses de forma oposta ao seu modo de vida. Desse modo, as formas convencionais de criar, plantar e produzir são desestruturadas em nome do capital. Consequentemente, formas de organização e de controle da produção e do tempo, distintas das dinâmicas locais, são adotadas. Ademais, as famílias camponesas são seduzidas pelo discurso de ascensão a condição de uma nova classe média rural.

Assim, nos municípios onde os projetos educacionais e de geração de trabalho e renda são implementados, passam a vigorar usos contrastados do mesmo espaço, e não é exagero 
dizer que, muitas vezes, essas múltiplas territorialidades desembocam em conflitos, às vezes, velados, às vezes explícitos.

A sustentação teórica-política-ideológica desse modelo para o campo desemboca na formação de agricultores/extrativistas/pescadores que não compreendem a conflitualidade como parte inerente ao processo de desenvolvimento do capitalismo. Na prática, os camponeses são impelidos a se reconhecer como agricultores familiares e/ou aquicultores cooptados pelo processo de tecnificação que lhes insere na condição de produtores. Em outras palavras, se tornam sujeitos compatíveis com as relações de mercado.

De modo geral, os camponeses que integram o projeto da Fundação Odebrecht são formados para: utilizar um pacote de alta tecnologia em lavouras/criatórios antes tratadas como secundários; ignorar os conflitos em torno do acesso à terra; substituir as discussões sobre as disputas para entrar e permanecer na terra, a conflitualidade e a luta de classes, pela proposição de compor a nova classe média rural; acreditar que é possível atingir o bem-estar individual e coletivo sob o modo de produção capitalista.

O modo como a Organização Odebrecht vem implementando seus projetos educacionais e de geração de trabalho e renda no campo baiano, merece uma reflexão especial. Em primeiro lugar, porque não é conduzida por uma agro-holding (OLIVEIRA apud FABRINI \& MARCOS, 2010) ou por uma empresa transnacional que controla o mercado de sementes e insumos. Tampouco, por uma corporação conhecida e reconhecida por desenvolver atividades agrícolas no campo brasileiro.

$\mathrm{Na}$ verdade, os diversos projetos são criados e implementados por uma Fundação, e não por uma organização econômica que comumente se destina a produção ou venda de mercadorias ou serviços tendo como único objetivo o lucro. Ademais, essa Fundação é um dos segmentos de um grupo empresarial (Odebrecht) que tem como "carro-chefe" a engenharia/construção civil e, em segundo lugar, a química/petroquímica. Por isso, essas investidas podem ser compreendidas como um pacto de aliança de classes em prol da legitimação e ampliação do capital.

Por fim, cabe mencionar que os projetos se sustentam nas relações interinstitucionais da Fundação Odebrecht com as três instâncias do governo brasileiro, além de empresas e instituições públicas que tem relação direta ou indireta com a agropecuária brasileira, sem que haja qualquer debate sobre a reforma agrária. Isso significa que o modelo de educação pelo trabalho se sustenta na articulação de algumas políticas públicas ou setoriais criadas pelo Estado. Dito de outro modo, o capital se articula com uma base organizacional formada por 
instituições públicas para manter o camponês, e toda a sua família, subordinado e dificultar a luta para entrar e permanecer na terra.

\section{REFERÊNCIAS}

BELUSSO, Diane. A integração de agricultores às cooperativas agrícolas abatedoras de frangos no oeste do Paraná. Presidente Prudente-SP: UNESP, 2011. (Doutorado em Geografia).

BRUNO, Regina Landim. LACERDA, Elaine. CARNEIRO, Olavo Brandão. Organizações da classe dominante no campo. In: MOLINA, Mônica Castagna (Org). Educação do Campo e pesquisa II: questões para reflexão. Brasília: MDA/MEC, 2010. p. 521-533. (Série NEAD Debate 20).

CALDART, Roseli Salete. Educação do Campo: notas para uma análise de percurso. In: MOLINA, Mônica Castagna (Org). Educação do Campo e pesquisa II: questões para reflexão. Brasília: MDA/MEC, 2010. p. 103-126. (Série NEAD Debate 20).

CAMACHO, Rodrigo Simão. Paradigmas em disputa na Educação do Campo. Presidente Prudente-SP: UNESP, 2013. (Doutorado Geografia).

CNPMF. Informativo Raiz \& Fruto, Cruz das Almas-BA, ano 22, n. 64, out./dez. 2010.

CONCEIÇÃO, Edney. Territorialidade da avicultura de corte na Bahia: o sistema integrado de produção avícola nos municípios de São Gonçalo dos Campos e Conceição da Feira - BA. Salvador: UFBA, 2007. (Mestrado em Geografia).

ETGES, Virginia Elisabeta. Sujeição e resistência: os camponeses gaúchos e a indústria do fumo. Santa Cruz do Sul-RS: Editora da FISC, 1991.

FABRINI, João Edmilson; MARCOS, Valéria de. Os camponeses e a práxis da produção coletiva. São Paulo: Expressão Popular/UNESP/Programa de Pós-graduação em Geografia, 2010. (Geografia em movimento). 
FISCHER, Fernando (Org.). Baixo Sul da Bahia: uma proposta de desenvolvimento territorial. Salvador: CIAGS/UFBA, 2007. (Coleção Gestão Social - Série Editorial CIAGS).

FONEC. Fórum Nacional de Educação do Campo. Notas para a análise do momento atual da Educação do Campo. Brasília-DF: Seminário Nacional FONEC, ago, 2012.

FUNDAÇÃO ODEBRECHT. Disponível em: <http://www.fundacaoodebrecht.org.br/> . Acesso em: 24 ago.2013.

Bases conceituais do Programa de Desenvolvimento Integrado e Sustentável do Baixo Sul da Bahia. Salvador: Fundação Odebrecht, 2011.

GERMANI, Guiomar Inez. Questão agrária e movimentos sociais: a territorialização da luta pela terra na Bahia. In: COELHO NETO, Agripino Souza; SANTOS, Ednusia Moreira Carneiro; SILVA, Onildo Araújo da (Orgs.). (Geo)grafias dos movimentos sociais. Feira de Santana-BA: UEFS Editora, 2010. p. 269-304.

A questão agrária na Bahia: permanências e mudanças. In: MENDONÇA, Franciso de Assis; LOWEN-SAHR, Cicilian Luiza; SILVA, Márcia da (Orgs). Espaço e Tempo: complexidade e desafios do pensar e fazer geográfico. Curitiba: ADEMADAN, 2009. p.348-370.

GONÇALVES, Alicia Ferreira. Cultura \& mercado no contexto transnacional: uma etnografia da Tecnologia Empresarial Odebrecht. São Paulo: UNICAMP, 2003 (Doutorado em Ciências Sociais).

GRÊMIO RECREATIVO ESCOLA DE SAMBA UNIDOS DE VILA ISABEL. Disponível em: <http://www.unidosdevilaisabel.com.br/>. Acesso em: 6 mai. 2013.

JACOBINA, Ronaldo. O empresário que foi longe. Revista Muito, Salvador-Ba, p.12-19, 5 out. 2008 . 
KUHN, Ednízia Ribeiro Araújo. Análise da Política de Educação do Campo no Brasil: meandros do PRONERA e do PRONACAMPO. Salvador: UFBA, 2015. (Doutorado em Geografia).

LIMA, Aline dos Santos. A territorialização do capital na lavoura de mandioca: a educação pelo trabalho da Aliança Estratégica do Amido no município de Laje (BA). (Doutorado em Geografia). Salvador: UFBA, 2017.

MASCARO, Alysson Leandro. Estado e reforma política. São Paulo: Boitempo, 2013.

ODEBRECHT, Norberto. Desenvolvimento sustentável: a visão e a ação de um empresário: o caso do Baixo Sul da Bahia. Salvador: CRA, 2004. (Série construindo os recursos do amanhã, v. 5).

Educação pelo trabalho: Tecnologia Empresarial Odebrecht. Salvador: Odebrecht, 1991.

ODEBRECHT S.A. Relatório Anual da Odebrecht S.A. 2015. Salvador: Odebrecht, 2016.

. Relatório Anual da Odebrecht S.A. 2014. Salvador: Odebrecht, 2015.

. Relatório Anual da Odebrecht S.A. 2013. Salvador: Odebrecht, 2014.

Relatório Anual da Odebrecht S.A. 2012. Salvador: Odebrecht, 2013.

Relatório Anual da Odebrecht S.A. 2011. Salvador: Odebrecht, 2012.

Relatório Anual da Odebrecht S.A. 2010. Salvador: Odebrecht, 2011.

Relatório Anual da Odebrecht S.A. 2009. Salvador: Odebrecht, 2010.

OLIVEIRA, Ariovaldo Umbelino de. Modo de produção capitalista, agricultura e reforma agrária. São Paulo: Labur Edições, 2007. 
. Modo capitalista de produção e agricultura. São Paulo: Ática, 1986. (Série Princípios).

ORGANIZAÇÃO ODEBRECHT. Disponível em: 〈http://odebrecht.com/>. Acesso em: 27 set. 2015 .

Disponível em: <http://odebrecht.com/>. Acesso em: 24 mar. 2016.

PAULINO, Eliane Tomiasi. Terra e vida: a Geografia dos camponeses no norte do Paraná. Presidente Prudente-SP: UNESP, 2003. (Doutorado em Geografia).

PELIANO, Anna Maria T. Medeiros (Coord.). Bondade ou interesse? Como e por que as empresas atuam na área social. Brasília: IPEA, 2001.

PERTILE, Noeli. Formação do espaço agroindustrial em Santa Catarina: o processo de produção de carnes no oeste catarinense. Florianópolis: UFSC, 2008. (Doutorado em Geografia).

PORTO, José Renato Sant'Anna. Poder e território no Baixo Sul da Bahia os discursos e os arranjos políticos de desenvolvimento. Rio de Janeiro: UFRRJ, 2016. (Doutorado em Ciências).

PRATA, Maria del Carmen López. A vida e a lida: estudos sobre trajetórias e projetos de vida de famílias de lavradores no interior do Estado da Bahia. Salvador: UFBA, 1994. (Mestrado em Sociologia).

REVISTA ODEBRECHT INFORMA. [S. I.]: Odebrecht S.A., 2004. Edição Histórica.

RIOCON. Fazendas Reunidas Rio de Contas Ltda. Disponível em: 〈http://riocon.com.br〉. Acesso em: 3 jun. 2014. 
SANDRONI, Paulo. Questão agrária e campesinato: a funcionalidade da pequena produção mercantil. São Paulo: Caramuru, 1980. (Coleção Teoria e História, v. 9).

SANTOS, José Vicente Tavares dos. Colonos do vinho: estudo sobre a subordinação do trabalho camponês ao capital. São Paulo: Hucitec, 1978.

SANTOS, Milton. A natureza do espaço: técnica e tempo; razão e emoção. 2.ed. São Paulo: Hucitec, 1997.

SEPLAN. Secretaria do Planejamento da Bahia. Disponível em: <http://www.seplan.ba.gov.br/>. Acesso em: 29 ago. 2015.

SILVA, Amenair Moreira. Autonomia e potencial transformador das ONGs: três casos no espaço rural. Salvador-BA: UFBA, 2002. (Mestrado em Geografia).

SORJ, Bernardo; PMPERMAYER, Malori J.; CORADINI, Odacir Luiz. Camponeses e agroindústria: transformação e representação política na avicultura brasileira. Rio de Janeiro: Zahar Editores, 1982.

STEDILE. João Pedro (Org.) A questão agrária no Brasil: o debate tradicional - 1500-1960. 2. ed. São Paulo: Expressão Popular, 2011. (p. 15-31).

TIRADENTES, Aparecida. Educação corporativa. In: CALDART, Roseli Salete et. al. (Orgs.). Dicionário da Educação do Campo. Rio de Janeiro: Escola Politécnica de Saúde Joaquim Venâncio; São Paulo: Expressão Popular, 2012. p. 247-252.

WANDERLEY, Maria de Nazareth Braudel. O camponês: um trabalhador para o capital. Cadernos de Difusão de Tecnologia, Brasília-DF, v. 2, n. 1, p. 13-78, jan./abr. 1985. 